\title{
A Phase I Trial to Determine the Pharmacokinetics, Psychotropic Effects, and Safety Profile of a Novel Nanoparticle-Based Cannabinoid Spray for Oromucosal Delivery
}

\author{
Stefan Lorenzl ${ }^{a}$, b, c Franz Gottwald $^{d}$ Angelika Nistler $^{\mathrm{e}}$ Laura Brehm $^{\mathrm{e}}$ \\ Renate Grötsch ${ }^{f}$ Georg Haber ${ }^{c}$ Christian Bremm ${ }^{g}$ Christiane Weck ${ }^{a, c}$ \\ Carina Trummer ${ }^{d}$ Werner Brand ${ }^{d, e}$ \\ anstitute of Nursing Science and Practice, Paracelsus Medical University, Salzburg, Austria; ${ }^{b}$ Department of \\ Palliative Care, University Hospital Munich, Ludwig-Maximilians-University, Munich, Germany; ' Department of \\ Neurology, University Hospital Agatharied, Hausham, Germany; ${ }^{\mathrm{d} C a n n a X a n ~ G m b H, ~ W a r n g a u, ~ G e r m a n y ; ~}{ }^{\mathrm{e}}$ Apurano \\ Pharmaceuticals GmbH, Warngau, Germany; ${ }^{\mathfrak{f} G e m e i n s c h a f t s p r a x i s ~ D r . ~ G r o ̈ t s c h ~ \& ~ D r . ~ H e i m e r, ~ H o l z k i r c h e n, ~ G e r m a n y ; ~}$ \\ 9Dürnbachstrasse 54a, Schliersee, Germany
}

\section{Keywords}

Pharmacokinetics · Safety · Cannabinoids · Oromucosal spray · Nanoparticles

\begin{abstract}
Introduction: A phase I, open-label clinical trial in healthy male subjects was conducted to assess the pharmacokinetic and safety profile of an oromucosal cannabinoid spray (AP701) containing a lipid-based nanoparticular drug formulation standardized to $\Delta$-9-tetrahydrocannabinol (THC). Methods: Twelve healthy male subjects received a single dose of AP701 (12 sprays) containing $3.96 \mathrm{mg}$ THC. Plasma samples were drawn $10 \mathrm{~min}-30 \mathrm{~h}$ post dose for analysis of THC and the active metabolite 11-hydroxy- $\triangle-9-\mathrm{THC}$ (11-OH-THC). Results: The single dose of the applied oromucosal cannabinoid spray AP701 (12 sprays, $3.96 \mathrm{mg} \mathrm{THC)} \mathrm{resulted} \mathrm{in} \mathrm{a} \mathrm{mean} \mathrm{maximum}$ plasma concentration $\left(C_{\max }\right)$ of $2.23 \mathrm{ng} / \mathrm{mL}(90 \% \mathrm{Cl} 1.22-3.24)$ and a mean overall exposure (area under the concentrationtime curve from time 0 to last measurable concentration [AUC O-t $\left._{\text {t }}\right)$ of $7.74 \mathrm{~h} \times \mathrm{ng} / \mathrm{mL}(90 \% \mathrm{Cl} 5.03-10.45)$ for THC. For the active metabolite $11-\mathrm{OH}-\mathrm{THC}$, a $C_{\max }$ of $2.09 \mathrm{mg} / \mathrm{mL}(90 \% \mathrm{Cl}$
\end{abstract}

karger@karger.com www.karger.com/mca

Karger

bOPEN ACCESS
(C) 2022 The Author(s)

Published by S. Karger AG, Basel

This is an Open Access article licensed under the Creative Commons Attribution-NonCommercial-4.0 International License (CC BY-NC) (http://www.karger.com/Services/OpenAccessLicense), applicable to the online version of the article only. Usage and distribution for commercial purposes requires written permission.
1.50-2.68) and $\mathrm{AUC}_{0-\mathrm{t}}$ of $10.4 \mathrm{~h} \times \mathrm{ng} / \mathrm{mL}(90 \% \mathrm{Cl} 7.03-13.77)$ was found. The oromucosal cannabinoid spray AP701 caused only minor psychotropic effects despite the relatively high dosage applied by healthy subjects. No serious adverse effects occurred. Overall, the oromucosal cannabinoid spray AP701 was well tolerated. Conclusion: Compared to currently available drugs on the market, higher AUC values could be detected for the oromucosal cannabinoid spray AP701 despite administration of a lower dose. These comparatively higher blood levels caused only minor psychotropic adverse effects. The oromucosal cannabinoid spray AP701 was well tolerated at a single dose of $3.96 \mathrm{mg}$ THC. The oromucosal administration may provide an easily applicable and titratable drug formulation with a high safety and tolerability profile.

(c) 2022 The Author(s)

Published by S. Karger AG, Basel

\section{Introduction}

Several galenic formulations and routes of administration (e.g., smoking, inhalation, oral, or oromucosal administration) are currently available for the medical ther- 
apy with cannabinoids. These formulations show considerable differences in bioavailability, patient compliance, and therapy success. Unsatisfactory pharmacokinetic profiles, occurrence of adverse effects and particularly poor bioavailability are typically prime reasons for unsatisfactory experiences with cannabinoid therapy [1-5].

Cannabinoids such as $\Delta$-9-tetrahydrocannabinol (THC) and cannabidiol (CBD) are well known to have poor oral bioavailability due to an extensive hepatic firstpass metabolism $[3,5,6]$. Before entering systemic circulation, orally administered cannabinoids permeate across the intestinal epithelial cell barrier and reach the liver via the portal circulation. In the liver, they undergo extensive biotransformation to the active metabolite 11-hydroxy- $\Delta$ 9-THC (11-OH-THC) and various inactive metabolites like 11-COOH-THC and others [7]. Metabolism of THC and $\mathrm{CBD}$ occurs by microsomal hydroxylation and oxidation catalyzed by CYP450 enzymes [8]. It can be assumed that up to $75 \%$ of an initial oral dose of cannabinoids is eliminated by the liver's first-pass metabolism before reaching its site of action [5]. Poor oral bioavailability of cannabinoids may not only reduce the effectiveness of the medication, but also increases the patient's therapeutic dose or the number of dose intervals to reach an adequate therapeutic effect [9]. Conversely, dose escalation of cannabinoids may increase the risk for undesired effects including psychotropic adverse effects. A convenient strategy to overcome the extensive first-pass metabolism in the liver as well as in the brush-border cells of the gastrointestinal tract is the oromucosal route of administration. After oromucosal administration drugs can be rapidly absorbed into the systemic circulation via venous drainage to the superior vena cava [10]. This direct absorption may dramatically enhance bioavailability of cannabinoids. Theoretically, only fractions of oral doses are required to reach and maintain the desired pharmacological response when THC is absorbed through the oral mucosa. For example, the commercially available standardized cannabis extract Sativex ${ }^{\circledR}$, which contains THC and CBD in an approximately $1: 1$ ratio, is marketed as an oromucosal spray for symptom improvement in adult patients with moderate to severe spasticity due to multiple sclerosis. A disadvantage of the formulation is the relatively high content of ethanol, which has been described to cause irritation and burn to the oral mucous membranes [11], and may thus affect the patient's adherence to the treatment regimen.

Another major concern with regard to oral administration of cannabinoids is the highly variable oral bioavailability including an inter- and intra-subject variability due to incomplete gastrointestinal absorption $[3,5]$.
In randomized controlled clinical trials, changes in seizure frequency and occurrence of adverse events (AEs) showed very large interindividual differences among patients receiving the same CBD dose $[5,12]$. High variability in the pharmacokinetic parameters was also observed for oral dronabinol (THC) capsules, which may have important implications for their safety and efficacy as well as patient compliance $[6,13,14]$.

Cannabinoids are practically insoluble in water and are therefore not soluble in the aqueous gastrointestinal or buccal fluids [2]. This impairs the permeation across biological membranes from aqueous matrices, and may lead to highly variable and potentially subtherapeutic plasma concentrations $[15,16]$. Poor drug solubility may lead to slow drug absorption, lack of dose proportionality, high inter- and intra-subject variability as well as possible gastrointestinal mucosal toxicity $[2,5,17]$. A more recent approach towards improved bioavailability is the formulation of cannabinoids in lipids.

Nanotechnology-based drug delivery systems containing lipid excipients show a particularly high potential for overcoming current challenges in cannabinoid therapy and enhance its bioavailability. Due to the small size, the nanoparticles exhibit unique physicochemical properties. Their high surface-to-volume ratio makes them especially attractive for the field of pharmaceutical drug [18]. For nearly spherical nanoparticles, a reduction in size from $10 \mu \mathrm{m}$ to $200 \mathrm{~nm}$ produces a 50 -fold increase in surface area-to-volume ratio, which is expected to have an impact on drug dissolution and therefore drug absorption [19]. Nanoparticulate drug delivery systems have previously been shown to increase the uptake and absorption of drugs across multiple biological barriers including the skin, the gastrointestinal tract as well as buccal or sublingual mucosa [10]. Lipid nanoparticles can contribute to a more uniform, reproducible, and more important enhanced oral bioavailability of lipophilic active pharmaceutical ingredients, e.g., cannabinoids [20].

The surface of such lipid-based nanocarriers can be covered with a hydrophilic layer to overcome poor aqueous solubility. The coated lipid nanoparticles are soluble in the aqueous environment of the human body (e.g., saliva or blood) and are able to transport the entrapped cannabinoids safely and rapidly to the systemic circulation and to their target site. Understanding critical aspects of the biopharmaceutical and pharmacokinetic profiles of cannabinoids, especially aspects strongly affecting the extent of oral absorption and metabolic elimination, is particularly important for the safe and effective use of cannabinoid-based drugs in clinical practice. 
For the first time, an innovative nanoparticulate drug formulation of the entire Cannabis sativa flower was designed, which combines several advantages to overcome current challenges in drug delivery of cannabinoids. First, oromucosal delivery in form of a cannabis spray circumvents hepatic metabolism and incomplete gastrointestinal absorption. Second, the nanoparticle technology enhances poor bioavailability of cannabinoids and contributes to a more uniform and less variable bioavailability, which is common for cannabinoids [19]. Third, the new design of the nanoparticle addresses low aqueous solubility of cannabinoids: The highly lipophilic cannabinoids are embedded and protected in a lipid nanocarrier, which is coated with a hydrophilic shell for optimal solubility in the aqueous environment of the human body. The pharmacokinetic and safety profile of the nanoparticle-based oromucosal spray developed for the delivery of a standardized dosage of cannabinoids was therefore examined in a pharmacokinetic study after a singledose application to healthy male subjects.

\section{Materials and Methods}

\section{Test Preparation}

The study preparation AP701 is an aqueous solubilized preparation of the whole decarboxylated flowers of Cannabis sativa $L$ (Cannabis flos, variety Bedrocan, supplied by the Dutch Office of Medicinal Cannabis OMC) with their full spectrum of constituents such as cannabinoids (THC and CBD.) and noncannabinoids (terpenes and flavonoids.) to be used as oromucosal spray. The whole flowers are milled to a particle size of $<0.4 \mu \mathrm{m}$, and the particles are solubilized as an oil-in water nano-suspension with the aid of excipients, without addition of ethanol or alcohol derivatives. AP701 contains $1.16 \%$ of Cannabis flos and is standardized by an in-house method to a content of $2.2 \mathrm{mg} / \mathrm{mL}$ THC and $<0.15$ $\mathrm{mg} / \mathrm{mL} \mathrm{CBD}$.

\section{Study Design}

The study was designed as a prospective, monocentric phase 1 , open-label, single-dose, single-arm clinical trial. The total duration of the study was $30 \mathrm{~h}$ from administration of the study preparation to the last blood sample taken. A screening visit took place 3 days prior to the administration of AP701. After signing the informed consent, the eligibility of each subject was checked by performing electrocardiography, by means of physical examination, and by collecting blood and urine samples.

\section{Inclusion Criteria}

Eligible subjects were healthy males between 35 and 60 years of age with a body mass index between 18 and $30 \mathrm{~kg} / \mathrm{m}^{2}$. Subjects were nonusers of tobacco products and in a general had a good health status (Karnofsky Score $=100$ ). Blood pressure, liver, and kidney function tests had to be within the normal range. A negative test result on HIV I, HIV II, hepatitis B cell surface antigen, hepatitis $C$ antibody as well as a negative test result of urine screening for Cannabis and illicit substance abuse was required.

\section{Exclusion Criteria}

Subjects with hypersensitivity or intolerance to Cannabis or to any of the excipients in the preparation, users of Cannabis products within 8 weeks prior to the study, and participants with a former or present history of dependence were not eligible to participate. Subjects with a present, former, or family history of mental or psychiatric illnesses were also excluded. Furthermore, individuals with acute severe somatic disease or a present cardiovascular, respiratory, diabetic, or cancer disease were not allowed to participate. Subjects taking any medication were excluded.

\section{Treatment and Dosing}

All participants came to the study center in a fasted state. A venous catheter was placed and the pre-dosing blood sample was taken. Thereafter, the participants received a standardized breakfast, followed by training by the medical staff for the correct administration of the study preparation with the aid of a dummy device. Thirty minutes after the placing of the venous catheter, the study preparation was applied. Each actuation of the oromucosal pump-action spray device delivered $150 \mu \mathrm{L}$ of AP701 with a content of $0.33 \mathrm{mg}$ THC and less than $0.02 \mathrm{mg}$ CBD. The single dose examined in this study comprised 12 actuations with a total of 3.96 $\mathrm{mg}$ THC and less than $0.27 \mathrm{mg}$ CBD. Each subject applied the spray to their oral mucosa once buccally on the right side, once buccally on the left side, and once sublingually. After $90 \mathrm{~s}$, the participant was allowed to swallow, whereupon the next 3 actuations were applied as described before. The single-dose application was completed after 4 repetitions (resulting in a total of 12 actuations). The application was closely monitored.

\section{Assessments}

Plasma samples were collected on Study day 1 pre-dose and at the following time points after the first actuation of the spray in the application of the study preparation: $10,15,20,30,45 \mathrm{~min}$, and 1, $1.5,2,3,4,5,6,7,8,24,26,28$, and $30 \mathrm{~h}$. The participants were continuously monitored for the occurrence of AEs. Moreover, the subjects were actively asked for any adverse observation at each time point for blood sampling.

In addition, a 17-item questionnaire on psychotropic drug effects was completed 3 min prior to each blood sampling. Each item was assessed on a numeric rating scale (NRS) ranging from 0 to 10 , with 0 standing for nonexistent and 10 for extreme expression of the queried condition. The list of questions was compiled in close accordance with the publication of Meyer et al. [21]. Each of the asked questions in this study is quoted in Table 1. Existing questionnaires on this topic are not sufficient suitable for the current research. The most commonly used Drug Effects Questionnaire assesses as 1 of 2 key aspects desirability of substance effects. Other subjective response instruments as UKU Psychotropic Side Effects Rating Scale or Profile of Mood States are too extensive to be repeated in the required frequent manner, and others are designed for specific substances. To reassess the subjects' cardiac, hepatic, and renal safety, electrocardiography was measured again and a final blood sample was taken at the end of Study day 2.

\section{Analytical Determinations}

The plasma concentration of THC and its metabolite 11-OHTHC was determined using a liquid chromatography - tandem mass spectrometry method with sufficient sensitivity and accuracy, specifically developed and validated for the purpose. The lower 
Table 1. Mean changes in psychotropic assessments (17-item numeric rating scale ranging from $0=$ nonexistent to $10=$ extreme expression of the queried condition)

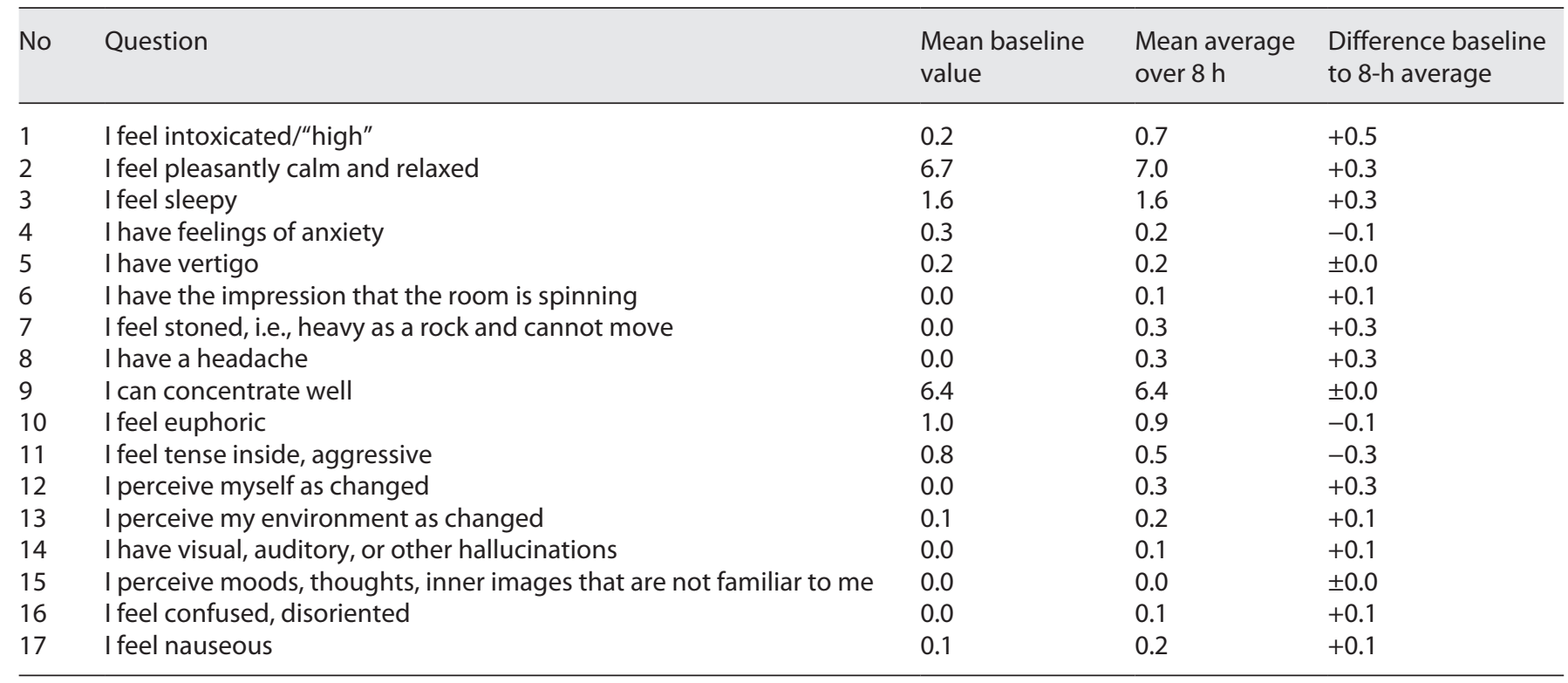

limit of quantification was identified as $0.25 \mathrm{ng} / \mathrm{mL}$. Detailed analytical validation data are provided as online supplementary material S1 (see www.karger.com/doi/10.1159/000521352 for all online suppl. material,).

The collection of the blood samples was performed in lithiumheparine tubes (Sarstedt, Nürnbrecht, Germany). The tubes were immediately inversed and stored at $4^{\circ} \mathrm{C}$. Within $30 \mathrm{~min}$, the tubes were gently shaken and then centrifuged for $10 \mathrm{~min}$ at $2,000 \mathrm{~g}$. The supernatant plasma was separated and stored at $-80^{\circ} \mathrm{C}$ prior to analysis.

Sample workup was performed as followed: $25 \mu \mathrm{L}$ of an internal standard solution containing the corresponding deuterized analytes were added to $300 \mu \mathrm{L}$ of plasma followed by the addition of $1,500 \mu \mathrm{L}$ of $1 \%$ acetic acid in acetonitrile. The samples were shaken for $10 \mathrm{~min}$ and treated in an ultrasonic bath for $30 \mathrm{~min}$ at $40^{\circ} \mathrm{C}$. The samples were then centrifuged at $16,000 \mathrm{~g}$ for $90 \mathrm{~min}$. The supernatant was dried by a SpeedDry Vacuum Concentrator $\left(55^{\circ} \mathrm{C}\right.$, $20 \mathrm{mbar}, 15 \mathrm{~h})$. The residue was redissolved in $100 \mu \mathrm{L}$ acetonitrile, treated in an ultrasonic bath $\left(10 \mathrm{~min}, 40^{\circ} \mathrm{C}\right)$ and centrifuged $(5$ $\min , 16,000 \mathrm{~g}$ ). The supernatant was used for LC-MS/MS measurements. Quality control samples and calibration curves were prepared and worked up simultaneously with the samples. Plasma from healthy, cannabinoid-naive volunteers was used as a reference. For method validation, spiked quality control samples were prepared.

\section{Study Endpoints}

The primary endpoint was the evaluation of pharmacokinetic data of THC: area under the concentration-time curve from 0 to infinite time, peak plasma concentration $\left(C_{\max }\right)$, and time to reach peak plasma concentration $\left(t_{\max }\right)$. Furthermore, the area under the concentration-time curve from time 0 to last measurable concentration $\left(\mathrm{AUC}_{0-\mathrm{t}}\right)$, area under the concentration-time curve from time $0-24 \mathrm{~h}$, area under the concentration-time curve from time $0-30 \mathrm{~h}$, the last measurable plasma concentration $\left(C_{\text {last }}\right)$, and the
Table 2. Trial subjects' demographic characteristics ( $n=12$, all male)

\begin{tabular}{lll}
\hline Age, years & Mean (SD) & $46.2(7.9)$ \\
& Range (min, max) & $23(36,59)$ \\
\hline Height, cm & Mean (SD) & $183.8(6.5)$ \\
& Range (min, max) & $22(172,194)$ \\
\hline Weight, kg & Mean (SD) & $81.9(9.4)$ \\
& Range (min, max) & $33(63,96)$ \\
\hline BMl, kg/m ${ }^{2}$ & Mean (SD) & $24.1(1.7)$ \\
& Range (min, max) & $5(21,26)$ \\
\hline
\end{tabular}

elimination half-life $\left(t_{1 / 2}\right)$ of THC were determined (see online suppl. glossary S2 for precise descriptions of the pharmacokinetic parameters). In addition, the same pharmacokinetic parameters were also quantified for 11-OH-THC.

\section{Statistical Methods}

Descriptive statistical methods were used for demographic and other baseline variables. A sample size of 12 subjects is in general considered sufficient to obtain measures of central tendency with acceptable mean variation and is therefore adequate to fulfill the study objectives, i.e., the evaluation of pharmacokinetic parameters and tolerability.

The pharmacokinetic calculations were performed by means of a noncompartmental analysis using the software Win-Nonlin Professional Edition Version 8.1 (Pharsight Corp., Mountain View, $\mathrm{CA}$, USA). The $\mathrm{AUC}_{0-\mathrm{t}}$ was calculated by the linear trapezoidal method.
Lorenzl et al. 
Table 3. Pharmacokinetics of THC after oromucosal administration of $3.96 \mathrm{mg}$ THC

\begin{tabular}{lllllllll}
\hline Parameter & Unit & $N$ & Mean (SD) & CV\% & Min & Median & Max & $90 \% \mathrm{Cl}$ \\
\hline AUC $_{0-\infty}$ & $\mathrm{h} \times \mathrm{ng} / \mathrm{mL}$ & 8 & $9.03(6.99)$ & 77.40 & 2.64 & 5.57 & 22.90 & $4.97-13.09$ \\
$\mathrm{AUC}_{0-\mathrm{t}}$ & $\mathrm{h} \times \mathrm{ng} / \mathrm{mL}$ & 12 & $7.74(5.70)$ & 73.60 & 1.73 & 5.29 & 21.40 & $5.03-10.45$ \\
$\mathrm{AUC}_{0-24}$ & $\mathrm{~h} \times \mathrm{ng} / \mathrm{mL}$ & 12 & $7.75(5.51)$ & 71.00 & 2.22 & 5.57 & 21.40 & $5.13-10.37$ \\
$\mathrm{AUC}_{0-30}$ & $\mathrm{~h} \times \mathrm{ng} / \mathrm{mL}$ & 12 & $8.09(5.79)$ & 71.60 & 2.22 & 5.57 & 22.00 & $5.34-10.84$ \\
$C_{\max }$ & $\mathrm{ng} / \mathrm{mL}$ & 12 & $2.23(2.12)$ & 95.20 & 0.66 & 1.68 & 8.86 & $1.22-3.24$ \\
$t_{\max }$ & $\mathrm{H}$ & 12 & $1.54(0.40)$ & 25.70 & 1.00 & 1.50 & 2.00 & $1.35-1.73$ \\
$C_{\text {last }}$ & $\mathrm{ng} / \mathrm{mL}$ & 12 & $0.39(0.18)$ & 46.50 & 0.25 & 0.30 & 0.71 & $0.30-0.47$ \\
$t_{\text {last }}$ & $\mathrm{H}$ & 12 & $8.42(6.93)$ & 82.40 & 4.00 & 6.50 & 30.00 & $5.13-11.71$ \\
$t_{1 / 2}$ & $\mathrm{H}$ & 8 & $3.50(2.96)$ & 84.50 & 1.09 & 1.85 & 8.25 & $1.78-5.22$ \\
\hline
\end{tabular}

Values of subjects were excluded when their $\mathrm{AUC}_{0-\mathrm{t}} / \mathrm{AUC}_{0-\infty}$ ratio or the adjusted $R^{2}$ value was $<0.80$.

Table 4. Pharmacokinetics of 11-OH-THC after oromucosal administration of $3.96 \mathrm{mg}$ THC

\begin{tabular}{lllllllll}
\hline Parameter & Unit & $N$ & Mean (SD) & CV\% & Min & Median & Max & $90 \% \mathrm{Cl}$ \\
\hline AUC $_{0-\infty}$ & $\mathrm{h} \times \mathrm{ng} / \mathrm{mL}$ & 10 & $11.50(8.52)$ & 73.80 & 3.87 & 9.57 & 30.30 & $7.07-15.93$ \\
$\mathrm{AUC}_{0-\mathrm{t}}$ & $\mathrm{h} \times \mathrm{ng} / \mathrm{mL}$ & 12 & $10.40(7.42)$ & 71.40 & 3.43 & 8.91 & 29.00 & $6.88-13.92$ \\
$\mathrm{AUC}_{0-24}$ & $\mathrm{~h} \times \mathrm{ng} / \mathrm{mL}$ & 12 & $10.40(7.10)$ & 68.10 & 3.89 & 8.91 & 28.00 & $7.03-13.77$ \\
$\mathrm{AUC}_{0-30}$ & $\mathrm{~h} \times \mathrm{ng} / \mathrm{mL}$ & 12 & $10.80(7.44)$ & 68.70 & 3.89 & 9.54 & 29.30 & $7.27-14.33$ \\
$C_{\max }$ & $\mathrm{ng} / \mathrm{mL}$ & 12 & $2.09(1.24)$ & 59.60 & 0.98 & 1.61 & 5.07 & $1.50-2.68$ \\
$t_{\max }$ & $\mathrm{H}$ & 12 & $1.67(0.54)$ & 32.20 & 1.00 & 1.50 & 3.00 & $1.42-1.92$ \\
$C_{\text {last }}$ & $\mathrm{ng} / \mathrm{mL}$ & 12 & $0.41(0.23)$ & 57.70 & 0.26 & 0.33 & 1.09 & $0.29-0.52$ \\
$t_{\text {last }}$ & $\mathrm{H}$ & 12 & $9.08(5.35)$ & 58.90 & 7.00 & 8.00 & 26.00 & $6.54-11.62$ \\
$\mathrm{t}_{1 / 2}$ & $\mathrm{H}$ & 10 & $4.94(3.97)$ & 80.30 & 0.93 & 3.76 & 11.40 & $2.88-7.00$ \\
\hline
\end{tabular}

Values of subjects were excluded when their $A \cup C_{0-t} / A U C_{0-\infty}$ ratio or the adjusted $R^{2}$ value was $<0.80 . A U C_{0-\infty}$ area under the concentration-time curve from 0 to infinite time; $A \cup C_{0-24}$, area under the concentration-time curve from time $0-24 \mathrm{~h} ; \mathrm{AUC}_{0-30}$, area under the concentration-time curve from time $0-30 \mathrm{~h}$.

\section{Results}

\section{Trial Population}

Twelve healthy male subjects were enrolled, all in conformity to the inclusion and exclusion criteria. Originally, 15 subjects were screened, but 3 persons had to be excluded due to elevated liver enzyme values, detection of morphine in blood sample, or out of range eGFR value, respectively. Demographic and other baseline characteristics of enrolled trial subjects are presented in Table 2.

\section{Pharmacokinetic Profile}

The pharmacokinetic results for THC and 11-OHTHC are summarized in Tables 3 and 4. Following the oromucosal administration of AP701, the mean $\mathrm{AUC}_{0-\mathrm{t}}$ of THC was found to be $7.74 \mathrm{~h} \times \mathrm{ng} / \mathrm{mL}$ (standard deviation [SD] 5.70, CV\% 73.6, 90\% CI 5.03-10.45) with a $C_{\max }$ of $2.23 \mathrm{ng} / \mathrm{mL}$ (SD 2.12, CV\% 95.2, 90\% CI 1.22-3.24) (Table 3). For the primary active metabolite 11-OH-
THC, the mean $\mathrm{AUC}_{0-\mathrm{t}}$ was $10.40 \mathrm{~h} \times \mathrm{ng} / \mathrm{mL}(\mathrm{SD} 7.42$, CV\% 71.4, 90\% CI 7.03-13.77) with a $C_{\max }$ of $2.09 \mathrm{ng} / \mathrm{mL}$ (SD 1.24, CV\% 59.6, 90\% CI 1.50-2.68) (Table 4). The mean plasma concentration-time curves of THC and 11-OH-THC including the SD are presented in Figures 1 and 2. AP701 seems to be rapidly absorbed with peak concentration levels for THC and 11-OH-THC at $1.54 \mathrm{~h}$ $\left(t_{\max }\right)(\mathrm{SD} 0.40, \mathrm{CV} \% 25.70,90 \%$ CI 1.35-1.73) and 1.67 $\mathrm{h}\left(t_{\max }\right)(\mathrm{SD} 0.54, \mathrm{CV} \% 32.20,90 \%$ CI 1.42-1.92), respectively. Whereas maximum plasma concentrations occur earlier for THC than for 11-OH-THC, elimination halflife for 11-OH-THC is longer compared to THC (Tables $3,4)$.

\section{Psychotropic Drug Effects}

Figures 3 and 4 visualize the reported outcome of the questionnaire on psychotropic drug effects with the first 8 assessments of the questionnaire depicted in Figure 3 and the remaining 9 assessments in Figure 4. For most of 


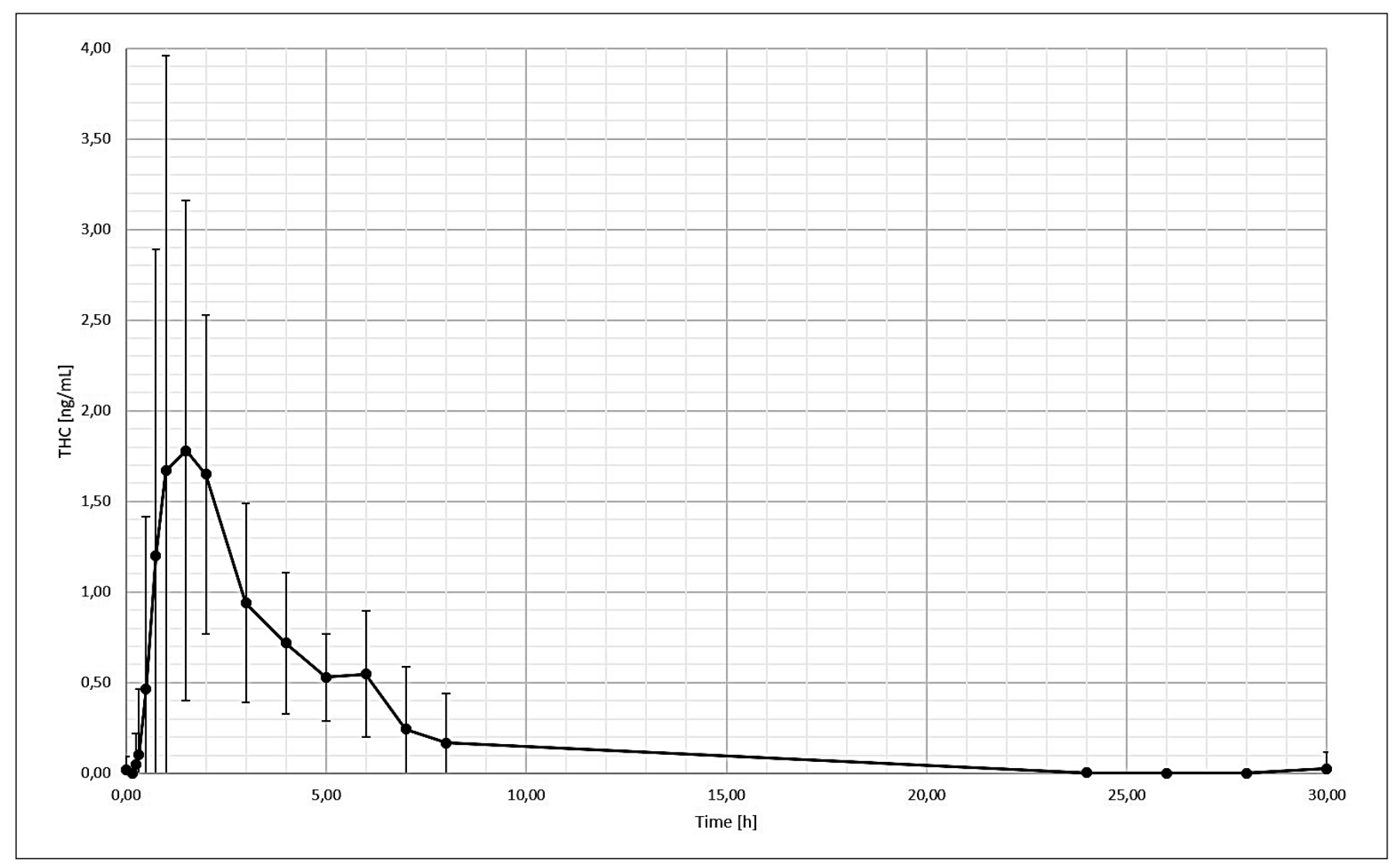

Fig. 1. Plasma level of THC after oromucosal administration of $3.96 \mathrm{mg}$ THC; values are means $\pm \mathrm{SD}(n=12)$.

the queried conditions, no major changes were reported over the course of time ( $30 \mathrm{~h}$ ). Only assessment No. 3 ("I feel sleepy") led to some variation with an increase in sleepiness after $2-4 \mathrm{~h}$ (Fig. 4). To compare the psychotropic conditions and their actual alterations more easily, differences between baseline values and subsequent values averaged over $8 \mathrm{~h}$ have been calculated (Table 1 ).

Generally, the differences from baseline to the average over $8 \mathrm{~h}$ were minor or negligible with a variation between -0.3 and +0.5 on the NRS (Table 1 ). None of the changes in symptoms were deemed clinically important. For example, the NRS value for intoxication changed from 0.2 at the start to 0.7 on average over $8 \mathrm{~h}$ (end of day 1 of the clinical trial). The maximum value was 1.0. No differences are present for the questions on vertigo, concentration, and unfamiliar moods. For the questions about anxiety, impression that the room is spinning, euphoria, environment changed, hallucinations, confusion, and nausea changes of -0.1 or +0.1 on the NRS scale are reported. Differences of -0.3 or +0.3 are documented for the questions about relaxation, sleepy, stoned, headache, aggressive, and self-changed.

\section{Adverse Events}

The single-dose administration of AP701 was generally well tolerated. A total of 20 treatment emergent adverse events (TEAEs) occurred in 9 of 12 subjects. Sixteen TEAE were of mild and 4 of moderate severity. No serious adverse event emerged. The duration of the individual TEAE varied from 3 min (AE: vestibular disorder) to $7 \mathrm{~h}$ (AE: headache). The mean and also the median duration for all TEAE was $2 \pm 1.93 \mathrm{~h}$. All AEs resolved spontaneously on the day of their occurrence. The causality of 16 of the 20 TEAE was assessed by the investigator as a certain, probable or at least possible relationship to treatment.

\section{Discussion and Conclusions}

\section{Pharmacokinetics}

The plasma concentration-time curve for THC (Fig. 1) shows that THC was rapidly absorbed following a single-
Lorenzl et al. 


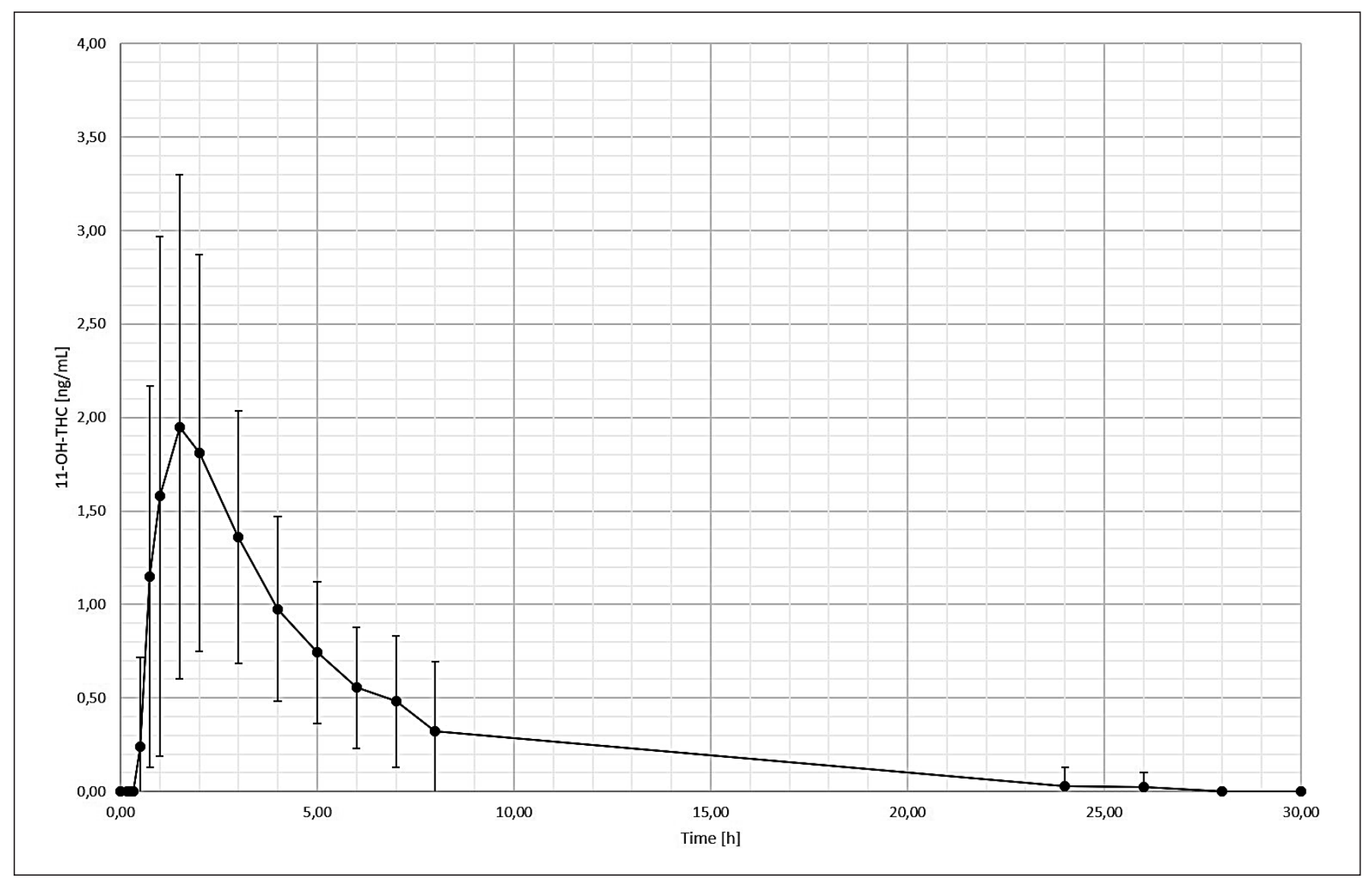

Fig. 2. Plasma level of 11-OH-THC after oromucosal administration of $3.96 \mathrm{mg}$ THC; values are means $\pm \mathrm{SD}(n=12)$.

dose administration in the form of this oromucosal spray. The single dose of the applied THC spray (12 actuations, $3.96 \mathrm{mg}$ THC) showed a mean maximum $C_{\max }$ of $2.23 \mathrm{ng} /$ $\mathrm{mL}$ at $t_{\max } 1.54 \mathrm{~h}$ with $\mathrm{t}_{1 / 2}$ at $3.5 \mathrm{~h}$ and a mean overall plasma concentration $\left(\mathrm{AUC}_{0-\mathrm{t}}\right.$ ) of $7.74 \mathrm{~h} \times \mathrm{ng} / \mathrm{mL}$ for THC (Table 3). In order to better interpret the above findings for the nanoparticulate THC spray AP701, it is compared to pharmacokinetic data of other THC-based cannabinoid drugs. However, this comparison is only intended to provide a rough overview as it is limited due to differences in general study settings, analytic methods, and in particular the fasted state of the study participants. For example, the THC plasma concentration $\mathrm{AUC}_{0-\mathrm{t}}$ of the oromucosal administered THC/CBD spray Sativex ${ }^{\circledR}$ (5.4 mg THC, $5.0 \mathrm{mg} \mathrm{CBD)} \mathrm{in} \mathrm{healthy} \mathrm{male} \mathrm{volunteers}$ resulted in $2.99 \mathrm{~h} \times \mathrm{ng} / \mathrm{mL}$, at a $C_{\max }$ of $1.48 \mathrm{ng} / \mathrm{mL}$ and $\mathrm{t}_{1 / 2}$ at $1.94 \mathrm{~h}[22]$ despite a $36 \%$ higher THC dosage compared to the tested nanoparticle THC spray AP701. In a pharmacokinetic analysis of the dronabinol oral solution of $4.25 \mathrm{mg} \mathrm{THC}$, an $\mathrm{AUC}_{0-\mathrm{t}}$ of $3.44 \mathrm{~h} \times \mathrm{ng} / \mathrm{mL}$ and $C_{\max }$ of $1.81 \mathrm{ng} / \mathrm{mL}$ were measured [6], which is also lower in comparison to the tested nanoparticle THC spray AP701, despite a higher dosage.

THC is well known to exhibit an extensive hepatic first-pass metabolism $[3,5,6]$ typically resulting in a high inter-subject variation in the pharmacokinetic profile $[6$, 23]. In our study, interindividual variability in overall exposure and maximum plasma concentrations of THC was moderate (CVs: area under the concentration-time curve from 0 to infinite time $77.4 \%, \mathrm{AUC}_{0-\mathrm{t}} 73.6 \%, C_{\max }$ 95.2\%). Further studies are required to evaluate the influence of the low number of probands and the beneficial effects of a nanoparticle drug delivery system on the interindividual variability.

\section{Psychotropic Drug Effects}

Psychotropic effects after smoking or inhaling Cannabis preparations are generally linked to a rapid increase of THC plasma concentrations and high $C_{\max }$ values including the active metabolite 11-OH-THC. Such effects are 


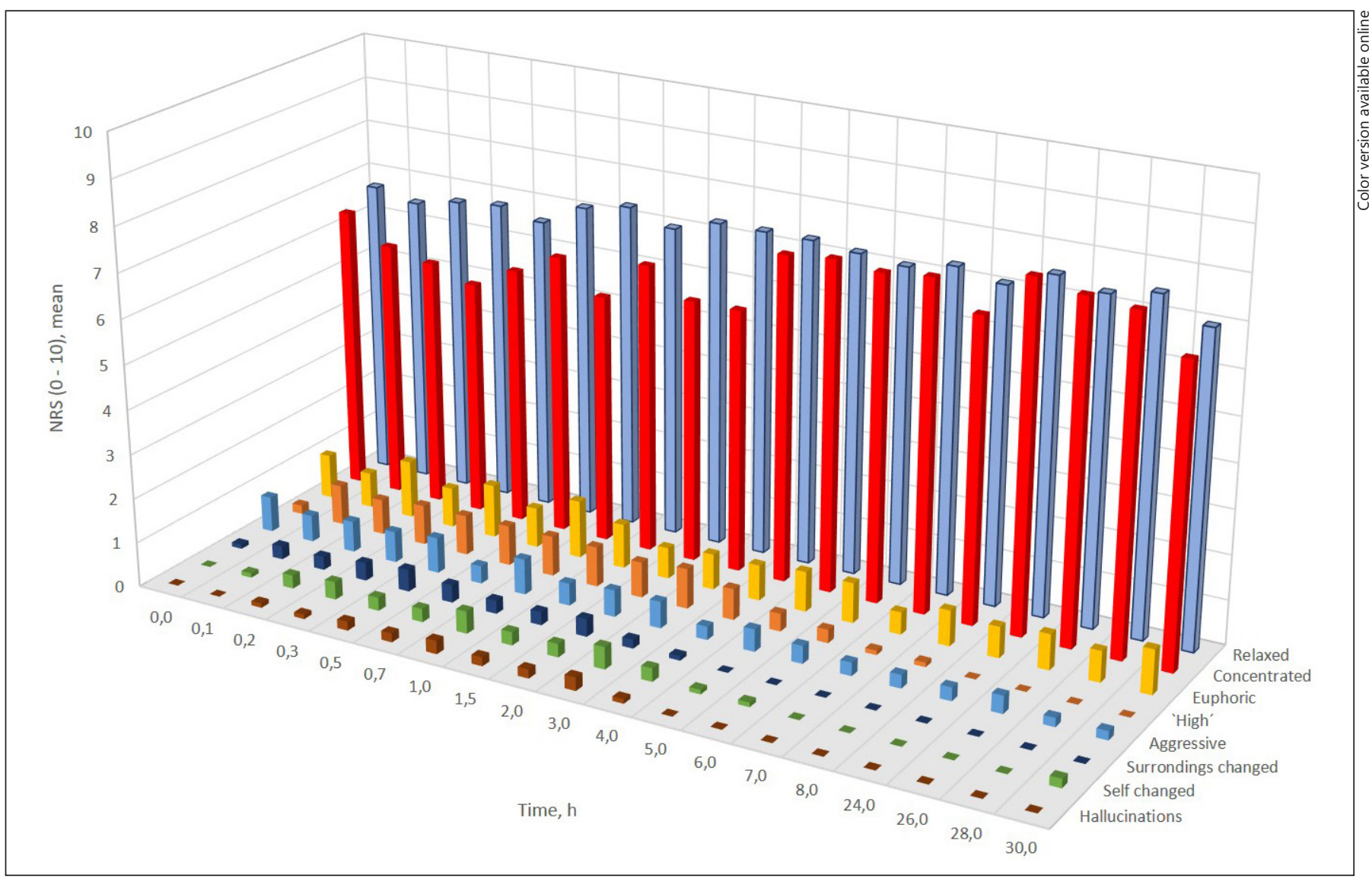

Fig. 3. Mean values for psychotropic drug effects (assessments 1-8) monitored for $30 \mathrm{~h}$ after oromucosal administration of $3.96 \mathrm{mg}$ THC $(n=12)$.

clearly not ideal in the context of daily medication with cannabinoids, e.g., in patients with chronic pain. The pharmacokinetic and psychotropic drug effects of a low dose inhaled THC-CBD solution (1:1) and a THC-CBD injection solution (1:1) were examined in a clinical trial with 11 healthy volunteers [21]. The total released THC dose of the inhaled THC-CBD solution was $0,648 \mathrm{mg}$, resulting in a $C_{\max }$ of $10 \mathrm{ng} / \mathrm{mL}$ and an $\mathrm{AUC}_{0-\mathrm{t}}$ of $1.83 \mathrm{~h} \times$ $\mathrm{ng} / \mathrm{mL}\left(t_{\max }=5 \mathrm{~min}\right)$. Despite an $84 \%$ lower dosage of the inhaled THC-CBD solution compared to the oromucosal application of AP701, the $C_{\max }$ was 4.5-times higher, but due to the rapid decline of THC after peaking the $\mathrm{AUC}_{0-\mathrm{t}}$ was 4.2-times lower [21]. Remarkably, however, the psychotropic drug effects were higher with the inhaled formulation, despite the lower absolute exposure to THC when compared with the present study.

The study preparation AP701 contains the same active components and is chemically identical to the compound drug formulation CannaXan 701-1.1, which is available in Germany and Austria. From a therapeutic point of view, it is important to ask whether the applied dosage of AP701 in this study and its respective psychotropic profile is of clinical relevance. Generally, prescribing physicians in Germany and Austria report on therapeutic daily dosages of 3-15 mg THC that is split into 3-4 takings of CannaXan 701-1.1 throughout the day (unpublished data). Hence, patients do not take more than $3.75 \mathrm{mg}$ THC ( $15 \mathrm{mg}$ split into 4 takings) at once, making the investigational dosage of $3.96 \mathrm{mg}$ THC in this study clinically relevant. Based on the collection of case reports in medical practices (unpublished data), the active components of AP701 show promising results with the mentioned dose scheme in patients suffering from chronic pain and other medical conditions like multiple sclerosis. This is in line with previous reports indicating a beneficial effect of cannabis on these indications due to its analgesic and spasmolytic properties but also through its extinction capability of aversive memories as evident in chronic pain [24,25].

The inhaled dose of $0.648 \mathrm{mg}$ THC in the publication of Meyer et al. [21] was considerably lower than the usu- 


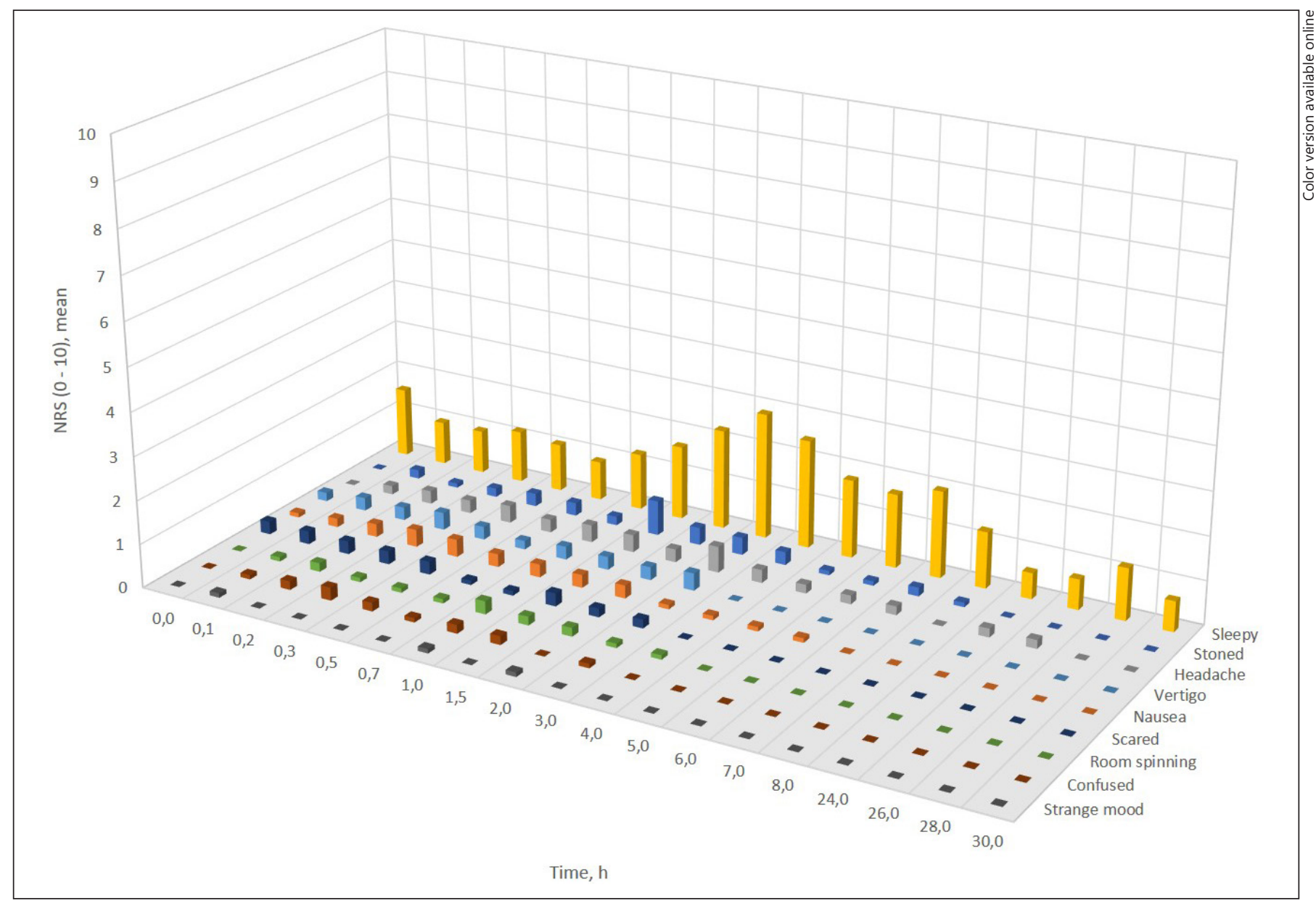

Fig. 4. Mean values for psychotropic drug effects (assessments 9-17) monitored for $30 \mathrm{~h}$ after oromucosal administration of $3.96 \mathrm{mg}$ THC $(n=12)$.

al therapeutic doses by inhalation, which would normally be around 30-50 mg THC per single dose (1-1.5 g Cannabis flos with a THC concentration of $200 \mathrm{mg} / \mathrm{g}$ taken in 6 equal dosages), and therefore rather aggravate the situation with the psychotropic effects. Cannabis smoking or inhaling typically leads to a rapid onset of cannabinoid effects within seconds or minutes, a high $C_{\max }$, and a fast decrease of the THC plasma concentration by $90 \%$ within $40 \mathrm{~min}$. The psychotropic effects do; however, last longer than the THC plasma levels might indicate, probably due to psychotropically active metabolites. This is usually discussed in the context of the potential for Cannabis abuse.

The rapid increase and decrease of THC plasma concentrations usually limit the therapeutic effects to approximately $2 \mathrm{~h}$. This decrease defines the intervals of single doses for sustaining the therapeutic effect level $[8$,
24], which are 6-8 times per day. This means chronically ill patient experience 6-8 times psychotropic drug effects per day, which often restrain them from a regulated daily job.

After oromucosal delivery of the AP701, first detectable THC concentrations could be found as early as 15 min post-dosing. Reaching the maximum plasma concentrations is slower than after smoking or inhalation, and the $C_{\max }$ is lower. This type of pharmacokinetics may be related to the observed absence of psychotropic effects. Plasma concentrations of THC were found above the lower limit of quantification of $0.25 \mathrm{ng} / \mathrm{mL}$ during $4-8 \mathrm{~h}$, in 1 subject even $30 \mathrm{~h}$ post-dosing. Consequently, a therapeutic level of the active ingredient may be sustained over a longer period of time - an observation that requires confirmation in an examination of steady-state pharmacokinetics. A decrease in dose intervals may be highly 
beneficial for chronic pain patients. Besides, the oromucosal spray offers a high flexibility in individual dosing and titrating the required quantity.

The occurrence of psychotropic effects may be related to active THC metabolites, of which 11-OH-THC is the first, formed in the liver through cytochrome P450 activity. This metabolite was even originally considered the major psychoactive substance in Cannabis sativa [23]. The kinetics of 11-OH-THC was also determined in this study and allows the calculation of a ratio of metabolite to parent compound. In this study, the ratio was 1.34 , solution [6], and 3.42 after the Sativex ${ }^{\circledR}$ mouth spray [22]. There is possibly a relation between this ratio and the occurrence of psychotropic adverse effects, which might be useful for the assessment of drug effect profiles of medical

As described before, there are always limitations comparing results of a certain clinical trial with data from literature, like differences in the general study setting, in the analytic methods or in the fasted state of the study participant. These different parameters also influence the comparability of the rations above. Generally, more detailed studies are required to assess the applicability and usefulness of such a ratio.

Overall, this single-dose trial showed pharmacokinetic characteristics confirming the clinical experience in patients with respect to dosing and dosing intervals. The trial is also in accordance with the clinical experience of no or only minor psychotropic adverse effects.

\section{Acknowledgments}

The authors would like to thank J. Fischböck-Halwachs and S. Stromer for sample preparation and mass spectrometry. We further thank A. Thiel and V. Scherer for their assistance in organizing this study and M. Schmidt for proof-reading the manuscript.

\section{Statement of Ethics}

This study was approved by the German Competent Authority BfArM (Federal Institute for Drugs and Medical Devices, reference No. 4044381, dated February 19, 2021) and received a positive vote of the Ethics Committee of the Medical Faculty of the LudwigMaximilians University of Munich (reference No. 20-0810 fed, dated February 4, 2021). The study was planned and performed according to the rules of the Good Clinical Practice (GCP) guidelines of the International Conference on Harmonization (ICH), the current version of the ethical principles stated in the Declaration of Helsinki, and German regulations. The clinical trial was registered with EudraCT (No. 2020-001073-67) and with Clinicalwhereas it was 2.93 after application of a dronabinol oral cannabis preparations.

Trials.gov under the registration number NCT04708795. Prior to the study, a written informed consent to participate in the study was obtained from each participant.

\section{Conflict of Interest Statement}

AP701 is manufactured by Apurano Pharmaceuticals GmbH, clinically developed as drug product, and marketed by CannaXan GmbH. S. Lorenzl, R. Grötsch, G. Haber, C. Bremm, and C. Weck were contracted to perform the clinical trial. A. Nistler and L. Brehm are employees of Apurano Pharmaceuticals GmbH, F. Gottwald, and C. Trummer are employees of CannaXan GmbH. W. Brand is Managing Director of both companies.

\section{Funding Sources}

This study was entirely funded by CannaXan GmbH.

\section{Author Contributions}

S.L., F.G., and W.B. designed and conceived the study. S.L. and F.G. supervised the study. F.G., A.N., L.B., C.T., and W.B. prepared the manuscript. S.L., R.G., G.H., C.B., and C.W. performed physical examinations and took blood samples. L.B. developed and validated the analytical setup to quantify metabolites by LC-MS/MS. All authors read, discussed, and approved the manuscript.

\section{Data Availability Statement}

The raw data that support the findings of this study are not publicly available, but pseudonymized data are available from the corresponding author (S.L.) upon reasonable request.

\section{References}

18
1 Karschner EL, Darwin WD, Goodwin RS, Wright S, Huestis MA. Plasma cannabinoid pharmacokinetics following controlled oral delta9-tetrahydrocannabinol and oromucosal cannabis extract administration. Clin Chem. 2011;57(1):66-75.

2 Kumar S, Bhargava D, Thakkar A, Arora S. Drug carrier systems for solubility enhancement of BCS class II drugs: a critical review. Crit Rev Ther Drug Carrier Syst. 2013;30(3):217-56. cokinetics and the pharmacodynamics of cannabinoids. Br J Clin Pharmacol. 2018;84(11): 2477-82.

4 Millar SA, Stone NL, Yates AS, O'Sullivan SE. A systematic review on the pharmacokinetics of cannabidiol in humans. Front Pharmacol. 2018;9:1365.

5 Perucca E, Bialer M. Critical aspects affecting cannabidiol oral bioavailability and metabolic elimination, and related clinical implications. CNS Drugs. 2020;34(8):795-800.
3 Lucas CJ, Galettis P, Schneider J. The pharma- 
6 Parikh N, Kramer WG, Khurana V, Cognata Smith C, Vetticaden S. Bioavailability study of dronabinol oral solution versus dronabinol capsules in healthy volunteers. Clin Pharmacol. 2016;8:155-62.

7 Fricker G, Langguth H, Wunderli-Allenspach H. Biopharmazie. Weinheim, Germany: Wiley-VCH Verlag GmbH; 2004.

8 Grotenhermen F. Pharmacokinetics and pharmacodynamics of cannabinoids. Clin Pharmacokinet. 2003;42(4):327-60.

9 Price G, Patel DA. Drug bioavailability. Treasure Island FL; 2021.

10 Hua S. Advances in nanoparticulate drug delivery approaches for sublingual and buccal administration. Front Pharmacol. 2019;10: 1328.

11 Scully C. Cannabis; adverse effects from an oromucosal spray. Br Dent J. 2007;203(6): E12.

12 European Medicines Agency. "Committee for medicinal products for human use (CHMP) assessment report: epidyolex"; 2019.

13 Wall ME, Sadler BM, Brine D, Taylor H, Perez-Reyes M. Metabolism, disposition, and kinetics of delta-9-tetrahydrocannabinol in men and women. Clin Pharmacol Ther. 1983; 34(3):352-63.
14 Ahmed AI, van den Elsen GA, Colbers A, van der Marck MA, Burger DM, Feuth TB, et al. Safety and pharmacokinetics of oral delta9-tetrahydrocannabinol in healthy older subjects: a randomized controlled trial. Eur Neuropsychopharmacol. 2014;24(9):1475-82.

15 Estler CJ, Schmidt H. Pharmakologie und Toxikologie für Studium und Praxis. Stuttgart: Schattauer-Verlag GmbH; 2006.

16 Savjani KT, Gajjar AK, Savjani JK. Drug solubility: importance and enhancement techniques. ISRN Pharm. 2012;2012:195727.

17 Kalepu S, Manthina M, Padavala V. Oral lipid-based drug delivery systems: an overview. Acta Pharmaceutica Sinica B. 2013;3(6):36172.

18 De Jong WH, Borm PJ. Drug delivery and nanoparticles:applications and hazards. Int J Nanomedicine. 2008;3(2):133-49.

19 Merisko-Liversidge E, Liversidge GG, Cooper ER. Nanosizing: a formulation approach for poorly-water-soluble compounds. Eur J Pharm Sci. 2003;18(2):113-20.
$20 \mathrm{Mu} \mathrm{H}$, Holm R, Müllertz A. Lipid-based formulations for oral administration of poorly water-soluble drugs. Int J Pharm. 2013; 453(1):215-24

21 Meyer P, Langos M, Brenneisen R. Human pharmacokinetics and adverse effects of pulmonary and intravenous THC-CBD formulations. Med Cannabis Cannabinoids. 2018; 1(1):36-43.

22 Stott CG, White L, Wright S, Wilbraham D, Guy GW. A phase I study to assess the single and multiple dose pharmacokinetics of THC/ CBD oromucosal spray. Eur J Clin Pharmacol. 2013;69(5):1135-47.

23 Huestis MA. Human cannabinoid pharmacokinetics. Chem Biodivers. 2007;4(8):1770804.

24 Whiting PF, Wolff RF, Deshpande S, Di Nisio M, Duffy S, Hernandez AV, et al. Cannabinoids for medical use: a systematic review and meta-analysis. JAMA. 2015;313(24):2456-73.

25 Marsicano G, Wotjak CT, Azad SC, Bisogno T, Rammes G, Cascio MG, et al. The endogenous cannabinoid system controls extinction of aversive memories. Nature. 2002 Aug 1;418(6897):530-4. 